\title{
BMJ Global Health Towards equity in global health partnerships: adoption of the Research Fairness Initiative (RFI) by Portuguese- speaking countries
}

\author{
António Carvalho, ${ }^{1}$ Carel IJsselmuiden, ${ }^{2}$ Kirsty Kaiser, ${ }^{2}$ Zulmira Hartz, ${ }^{1}$ \\ Paulo Ferrinho ${ }^{1}$
}

To cite: Carvalho A,

IJsselmuiden C, Kaiser K, et al. Towards equity in global health partnerships: adoption of the Research Fairness Initiative (RFI) by Portuguese-speaking countries. BMJ Glob Health 2018;3:e000978. doi:10.1136/ bmjgh-2018-000978

Handling editor Seye Abimbola

Received 25 May 2018

Revised 8 August 2018

Accepted 9 August 2018

Check for updates

C) Author(s) (or their employer(s)) 2018. Re-use permitted under CC BY-NC. No commercial re-use. See rights and permissions. Published by BMJ.

${ }^{1}$ Global Health and Tropical Medicine Research Centre, Universidade Nova de Lisboa, Instituto de Higiene e Medicina Tropical, Lisboa, Portugal ${ }^{2}$ Council on Health Research for Development, Geneva, Switzerland

\section{Correspondence to} Dr António Carvalho; antoniomanuelcarvalho@gmail. com
Research partnerships between high-income countries (HICs) and low- and medium-income countries (LMICs) often display a set of asymmetries that hinder the development of science, technology and health systems in the LMICs. In practice, this means that research partnerships, instead of addressing local priorities, often result in the appropriation of local data, the relegation of southern scientists to the category of 'field experts', the publication of research papers in high-impact journals without LMIC partners as coauthors and the tokenisation of LMIC partners and institutions to obtain competitive funding. ${ }^{12}$ There are numerous studies on power imbalances pertaining to research partnerships, often calling for general or specific interventions to improve them, but without apparent actual change in practice. ${ }^{3-5}$

Over the past 20 years, only two explicit guidelines have been developed to tackle these imbalances. The Canadian Coalition for Global Health Research (CCGHR) developed a set of recommendations, focused on six main principles, to promote ethical partnerships, including the use of innovative methodologies. ${ }^{6}$ The Commission for Research Partnerships with Developing Countries (KFPE) ${ }^{7}$ has also advocated the use of 11 principles which deal with a wide range of issues, from agenda setting to dissemination. The work of KFPE is 20 years old, but it is not well known outside Switzerland; moreover, it does not provide a practical framework to assess how these principles are implemented in research projects and actual collaborations.

Other agencies involved in the advocacy of ethical research partnerships include the United States Agency for International Development, the Dutch Ministry of Foreign Affairs, the International Development
Research Centre (Canada) and the Norwegian Programme for Development, Research and Education (NUFU). ${ }^{8}$ The Sustainable Development Goal (SDG) 17 is focused on partnerships as means to achieve the other SDGs, recognising that joint research in health and other fields is essential.

Funders of research partnerships are struggling with equalising the balance between countries and institutions. The United Kingdom's Collective on Development Sciences (UKCDS) published a survey of research funder efforts to achieve more equitable research partnerships in $2017^{9}$ while, in the same year, the UK's Independent Commission for Aid Impact (ICAI) published a report indicating substantial weaknesses in specifying, assessing and improving equity in research partnerships supported by the UK Grand Challenges Research Fund. ${ }^{10}$

While the intentions behind these initiatives are sincere, one may question whether they have practical implications, especially due to the absence of a metric or framework to assess their impact. The Research Fairness Initiative (RFI) was developed through wide global consultation by the Council on Health Research for Development (COHRED) between 2015 and 2017. It is a pragmatic tool that encourages all key stakeholders in global research collaborations to report on their approaches, policies and practices in relation to the partnership components of research. The RFI aims at creating transparency, enabling partners to negotiate before partnerships happen, increasing trust and sense of co-ownership, and building a growing global evidence base of best practices, guidelines and standards. ${ }^{11}$ The RFI can be understood as a "compliance tool' that promotes knowledge and use 
of already existing good practices and identifies areas where more work is required or where benchmarks can be developed.

The main difference between the RFI and previous initiatives is the attempt to go beyond 'good intentions', as it is a compliance mechanism which builds on a growing body of evidence on all aspects related to partnerships. This tool can be implemented by a wide range of institutions such as government departments, national research and innovation agencies, academic and research institutions, funders, philanthropies and the private sector.

The Special Programme for Research and Training in Tropical Diseases (TDR) was the first institution to prepare an RFI Report, publicly available since early 2018, and the Institute of Hygiene and Tropical Medicine of the NOVA University of Lisbon (IHMT/NOVA) has recently published their RFI Report. IHMT/NOVA was founded in 1902 and has been at the forefront of research on tropical diseases, often within networks and partnership projects, warranting IHMT/NOVA a strong international presence. IHMT/NOVA is particularly active within the Community of Portuguese Speaking Countries (CPLP). Research partnerships are supported by a wide range of national and international funding schemes and institutions. Some of them are specifically focused on the CPLP area, such as the 'Partnerships for development' programme of the Calouste Gulbenkian Foundation, as well as the Aga Khan Development Network. The Portuguese Foundation for Science and Technology often supports collaborative projects within the CPLP. In 2013, Portugal and Unesco signed an agreement establishing the International Centre for Advanced Training of Scientists from Portuguese-Speaking Countries in the Areas of Basic Sciences. ${ }^{12}$

Over the years, several networks have been developed within the CPLP to foster health collaboration understood in a broad sense, encompassing aspects related to governance, research, education and training of human resources. ${ }^{13}$ These networks are fundamental in the establishment of research partnerships and priorities, and include PECS-CPLP (Strategic Plan for Health Cooperation within the CPLP) (2009-2016, new edition in preparation); RINSP-CPLP (Network of National Institutes of Health in the CPLP) (2011-); RETS-CPLP (Network of Technical Health Schools) (2009-); Medical Education Network-CPLP; Network of Telemedicine-CPLP. ${ }^{14}$ The main difference between the CPLP and other intergovernmental organisations that emerged after the fall of colonial empires-such as the Commonwealth or the International Organisation of La Francophonie-is that it is not led by the Global North country-Portugal-in part due to the socioeconomic, demographic and diplomatic importance of Member States such as Brazil and Angola. ${ }^{15}$

IHMT/NOVA spearheaded RFI's adoption by the Ministers of Health of CPLP Member States at their biennial meeting in Brasilia, Brazil, in October 2017. ${ }^{16}$ This led to the recommendation that the guiding principles and mechanisms of the RFI should be built into the scientific work of RINSP (Network of Public Health Institutes of the CPLP) and RIDES (Health Research and Development Networks of the CPLP). In April 2018, at the second joint meeting of RIDES, representatives of all Member States reiterated that "the guiding principles and mechanisms of the Research Fairness Initiative (RFI) should become 'structuring scientific principles' within RIDES". ${ }^{17}$

The adoption of the RFI by IHMT/NOVA and the CPLP is an opportunity for the users of the RFI and for the RFI System itself. First, for IHMT/NOVA, the writing of its own RFI Report led to an institution-wide reflection on its own relationships with research partners. The first finding is a confirmation that IHMT/ NOVA has taken substantial steps to overcome its own colonial past in the way it constructs and manages its research partnerships. For instance, IHMT/NOVA's Administration Board, Advisory Council and Scientific Advisory Board include members from partner institutions from several countries from the Global South, and there are numerous institutional partnerships with Universities in Angola, Brazil, Cape Verde and Mozambique. ${ }^{18}$ IHMT/NOVA also incorporates academic staff from those Universities as Invited Professors. One of the outcomes of this change is that several training programmes were moved from Portugal to Angola, Brazil and Cape Verde. IHMT/NOVA has also participated in several collaborative research projects coordinated by LMIC institutions. However, the systematic nature of the RFI also indicated areas for further improvement, the main one being the lack of guidelines and clear policies on data sharing, public engagement with science and dissemination of IHMT/NOVA's research.

Second, for the CPLP, the implementation of the RFI is likely to lead to a greater institutional awareness towards issues of fairness between partners and institutions with greatly differing research capabilities. The CPLP fosters cooperation between Portugal and a group of countries in Africa, South America and Southeast Asia that were once its former colonies. The CPLP was founded in 1996, 22 years after the Carnation Revolution in Portugal-the Fascist elite was removed from power, bringing an end to colonial rule. The CPLP is characterised by a sense of togetherness and solidarity and is focused on the promotion of the Portuguese language, a common ground to establish partnerships and cooperation in various fields, such as culture and health. ${ }^{19}$

Third, because the RFI is an open and evolving system, use of the RFI within CPLP will enable adaptation to its cultural and epistemological characteristics. As Jasanoff ${ }^{20}$ argued, there are numerous 'civic epistemologies' which characterise national models of knowledge production and public accountability. The recent adoption of the RFI 
by the CPLP may contribute to further development and expansion of this mechanism, incorporating new methodological approaches and historical work related to public engagement with science, technology and health in Latin America and Africa. ${ }^{21}$ This could be interpreted as a form of 'reverse innovation', ${ }^{22}$ as experiences and approaches from LMICs can be mobilised to reconfigure compliance tools themselves, thus contributing to an ecology of knowledge and practices. A good example of 'reverse innovation', especially in the field of vector-borne infectious tropical diseases, is the fact that clinicians from LMICs usually have a much richer empirical experience than their HIC counterparts, as they work in regions where those diseases are endemic - their experience is of major importance to address these diseases as they emerge in countries like Portugal, France, Italy and Greece.

It is too early to state whether the RFI will be an opportunity to transform institutional practices, eventually leading to stronger research partnerships, but IHMT/NOVA's expectation is that CPLP-wide implementation of the RFI will substantially support the research capabilities of all member states. The adoption of the RFI allows institutions to include the RFI Logo on their websites, reports and other relevant materials, thus enhancing their 'ethical capital'. Notions such as 'corporate social responsibility', 'responsible business', 'sustainability' and recent debates linked to UK's Research Excellence Framework(REF), focusing on 'impact', ${ }^{23}$ illustrate how ethical capital is mobilised by public and private organisations as part of their brand management strategies. ${ }^{24}$ Funding agencies themselves increasingly require researchers to frame their research proposals according to SDGs, and it is possible that in the near future certain compliance tools-such as the RFIwill be mandatory to ensure the ethical/moral integrity of a given institution.

The RFI Logo is valid for an initial period of 2 years, and it can be extended if RFI principles and guidelines are put in place by the adhering organisation-this process is monitored by COHRED, which aims at involving all relevant stakeholders in global health research. The preparation of an institutional RFI Report by any of the key stakeholder groups-government departments with responsibilities in research and science, national research and innovation agencies, research and academic institutions, corporations engaged in research, research funders, and international agencies and non-profits-can provide transparency in terms of their own role in generating equitable partnerships, also creating a global evidence base of good practices and, possibly, future benchmarks and standards. We are still in the early days of the RFI, and wider implementation and further research will be necessary to assess whether the adoption of the RFI by the CPLP will contribute to the empowerment of local institutions and to the transformation of the RFI itself.

Some of the indicators that could be used to assess the impact of the RFI on partnerships might include, for instance, the number of collaborative research projects coordinated by LMIC institutions; the number of peer-reviewed articles where the first author belongs to a LMIC institution; the number of patents registered by LMIC partner institutions or the number of new PhDs awarded to LMIC candidates stemming from collaborative research projects. These indicators may illustrate how the RFI benefits LMIC institutions, but a more comprehensive and systematic protocol still needs to be developed. Nevertheless, the experience at the IHMT/NOVA shows that preparing an RFI Report fosters greater awareness of all aspects of research partnerships, demonstrating that institutional ethics are deeply entwined with research management systems.

Contributors The authors contributed equally to the development of this article.

Funding The authors have not declared a specific grant for this research from any funding agency in the public, commercial or not-for-profit sectors.

Competing interests $\mathrm{Cl}$ is the executive director of the Council on Health Research for Development. KK is the Research Fairness Initiative Implementation Manager.

Patient consent Not required.

Provenance and peer review Not commissioned; externally peer reviewed. Data sharing statement No additional data are available.

Open access This is an open access article distributed in accordance with the Creative Commons Attribution Non Commercial (CC BY-NC 4.0) license, which permits others to distribute, remix, adapt, build upon this work non-commercially, and license their derivative works on different terms, provided the original work is properly cited, appropriate credit is given, any changes made indicated, and the use is non-commercial. See: http://creativecommons.org/licenses/by-nc/4.0/

\section{REFERENCES}

1. Edejer TT. North-South research partnerships: the ethics of carrying out research in developing countries. BMJ 1999;319:438-41.

2. Nordling L. Africa aims for research autonomy: regional hub intends to manage international grants and develop science strategy. Nature 2015;520:142-3.

3. Noormahomed EV, Mocumbi AO, Preziosi M, et al. Strengthening research capacity through the medical education partnership initiative: the Mozambique experience. Hum Resour Health 2013;11:62.

4. Parker M, Kingori P. Good and bad research collaborations: researchers' views on science and ethics in global health research. PLoS One 2016;11:e0163579.

5. Zumla A, Huggett J, Dheda K, et al. Trials and tribulations of an African-led research and capacity development programme: the case for EDCTP investments. Trop Med Int Health 2010;15:489-94.

6. CCGHR (Canadian Coalition for Global Health Research). 2015.CCGHR Principles for Global Health Research. http://www. ccghr.ca/wp-content/uploads/2015/10/CCGHR-Principles-for-GHR-FINAL.pdf (accessed 15 May 2018).

7. KFPE (Commission for Research Partnerships with Developing Countries). A guide for transboundary research partnerships. Switzerland: Swiss Academy of Sciences, 2014.

8. Carvalho A, IJsselmuiden C, Klipp K, et al. A Implementação da iniciativa para a Equidade na Investigação. An Inst Hig Med Trop. 2017;16:11-20.

9. Dodson J, 2017. Building partnerships of equals. UK collaborative on development science. http://www.ukcds.org.uk/sites/default/files/ content/resources/Building\%20Partnerships\%20of\%20Equals_\% 20REPORT\%20\%282\%29.pdf (accessed 15 May 2018).

10. ICAI (Independent Commission for Aid Impact). 2017.Global challenges research fund - a rapid review. https://icai.independent. gov.uk/report/gcrf/ (accessed 15 May 2018).

11. COHRED (Council on Health Research for Development. 2017.Research fairness initiative evidence base. http://rfi.cohred.org/ rfi-evidence-base/ (accessed 7 Aug 2018).

12. UNESCO. 2013.UNESCO and portugal signed an agreement on a category 2 centre in the sciences. http://www.unesco.org/new/en/ natural-sciences/about-us/single-view/news/unesco_and_portugal signed_an_agreement_on_a_category_2_cent/ (accessed 15 Jul 2018). 
13. Ferrinho P. Hartz, Z. O PECS: instrumento estruturante da reflexão e da cooperação em saúde entre os Estados membros da CPLP. An Inst Hig Med Trop 2016;15:5-6.

14. Lapão L V, Ferrinho P. A strategic roadmap for telehealth in the community of Portuguese-speaking countries. Policy in Focus 2016;13:47-9.

15. Bondoso A. CPLP e lusofonia na globalização. Porto: Universidade Lusíada, 2012.

16. COHRED(Council on Health Research for Development), 2017. Community of Portuguese Language Countries (CPLP) approves declaration to adopt the RFI. http://rfi.cohred.org/3820/communityof-portuguese-language-countries-cplp-approves-declaration-toadopt-the-rfi/ (accessed 7 Aug 2018).

17. CPLP(Community of Portuguese Language Countries). 2018.Brasília declaration. https://www.cplp.org/id-3333.aspx? $\mathrm{PID}=8757 \& M=$ NewsV2\&Action $=1 \&$ Newsld $=5712$ (accessed 7 Aug 2018).
18. Fresta MJ, Ferreira MA. Estabelecimento de uma rede da cooperação em educação médica, no âmbito do PECS-CPLP. Anais Do Instituto De Higiene E Medicina Tropical 2016;15:27-34.

19. Power M. The commonwealth, 'development' and post-colonial responsibility. Geoforum 2009;40:14-24.

20. Jasanoff S. Designs on nature: science and democracy in Europe and the United States. Princeton, NJ: Princeton University Press, 2005.

21. Fleury S. Brazil's health-care reform: social movements and civil society. Lancet 2011;377:1724-5.

22. Govindarajan V, Ramamurti R. Reverse innovation, emerging markets, and global strategy. Global Strategy Journal 2011;1:191-205.

23. Watermeyer R, Hedgecoe A. Selling 'impact': peer reviewer projections of what is needed and what counts in REF impact case studies. A retrospective analysis. J Educ Policy. 2016;31:651-65.

24. Kitchin T. Corporate social responsibility: a brand explanation. $J$ Brand Manag 2003;10:312-26. 